\title{
Giant Cicada Emergence, Protandry and Chorus Centers Formation as Revealed by Studies Using a Sound Trap
}

\author{
Samuel de Carvalho Andrade ${ }^{1,2}$ (D) Nilza Maria Martinelli $^{1}$ • \\ Guilherme D. Rossi ${ }^{1}$ - Daniel J. Andrade ${ }^{1}$
}

Revised: 5 May 2017 / Accepted: 11 May 2017 /

Published online: 23 May 2017

(C) Springer Science+Business Media New York 2017

\begin{abstract}
The giant cicada, Quesada gigas (Olivier) (Hemiptera: Cicadidae), is an important coffee pest and information about the behavior and reproduction of this species, e.g. emergence, senescence and ovarian maturation status, can be valuable to understand giant cicada ecology and to improve the use of a sound trap as a control method. A great number of Q. gigas adult males and females was captured using a sound trap and a protandrous type of emergence possibly associated with chorus centers formation was observed. All giant cicadas collected until 14-15 days after the beginning of male emergence (DAME) had immature ovaries at two different years of evaluation. On the other hand, the majority of cicadas collected from 20 until 48 DAME had mature ovaries with visible chorionated oocytes. Despite the use of the sound trap to collect insects for ecological studies, we believe that next generations of $Q$. gigas can be reduced by using this sound trap to hinder the formation of giant cicada chorus centers, to reduce male availability to copulate with females and to reduce the number of females to oviposit in coffee plants.
\end{abstract}

Keywords Coffea arabica $\cdot$ Quesada gigas $\cdot$ phonotaxis $\cdot$ behavioral control

\section{Introduction}

The giant cicada Quesada gigas (Olivier, 1790) (Hemiptera: Cicadidae) is widely distributed in the Americas from North America to Argentina (Metcalf 1963; Martinelli and Zucchi 1997). Giant cicada has five underground nymphal instars (Maccagnan and

Samuel de Carvalho Andrade

samuelcarvalhoandrade@yahoo.com.br

1 School of Agricultural and Veterinarian Sciences, São Paulo State University (Unesp), Jaboticabal, Brazil

2 Departamento de Fitossanidade, Via de Acesso Prof. Paulo Donato Castellane s/n, Jaboticabal, SP 14884-900, Brazil 
Martinelli 2004) with the immature stage lasting approximately two years (Souza et al. 2007). At the end of immature stage, last instars with visible wing buds dig up tunnels towards the soil surface, leave the underground and climb into host trunks and branches where they stay quiescent for nearly two hours. After this quiescent period, last instars cuticles are broken at the ecdysis line and adult cicadas emerge (Souza et al. 2007).

In Brazil, Q. gigas nymphs represent a major coffee pest in the south of Minas Gerais State and the northeast of São Paulo State (Martinelli and Zucchi 1997; Martinelli 2004). The emergence of $Q$. gigas starts in September and female attraction for mating occurs by the emission of a characteristic and loud male calling song (Maccagnan 2008). After mating females lay their eggs inside dry branches preferentially in the upper third of the canopy of coffee plants (Decaro Junior et al. 2012).

Control of Q. gigas in coffee plantations is mainly done since 1980 by the application of systemic insecticides in the soil (Reis et al. 2002). Nevertheless, most of these insecticides have been banned from the market due to their high toxicity to man and to the environment. The most recent case of insecticide withdrawal for giant cicada control in Brazil occurred in 2006 when the active ingredient aldicarb, widely used to control cicadas in coffee orchards in the past, was removed from the market.

The constant increase of public demand for reduction in the use of broad-spectrum insecticides has been guiding the development of new pest control techniques (Ishaaya and Horowitz 2009). In this scenario, behavioral manipulation of insects appears as an interesting alternative (Foster and Harris 1997). Sound traps for insects were first used in 1949 to attract Anopheles albimanus Wiedemann, 1820 (Diptera: Culicidae) (Kahn and Offenhauser 1949; Offenhauser and Kahn 1949). A sound trap broadcasting male calling songs to investigate acoustical behavior of cicadas and other acoustic methods have been used to disrupt insect behavior or for insect collection (Alexander and Moore 1958; Walker 1988; Mankin 2012).

Aiming to reduce the amount of highly toxic systemic insecticides used to control $Q$. gigas, a sound trap that broadcasts the calling song of $Q$. gigas males was developed (Maccagnan 2008). This device broadcasts a sound identical to that produced by males of $Q$. gigas throughout the field attracting females of giant cicada to the device. After attraction the cicadas can be killed by the application of insecticides or be manually collected for biological assays.

The understanding of reproductive traits of the target species is necessary to improve the use of sound traps (Mankin 2012) and some aspects regarding the reproduction of Q. gigas are still unknown. The objective of this study was to determine the ovarian maturation and the pattern of male/female emergence of $Q$. gigas captured at different dates after the beginning of the emission of the male calling song as a theoretical subside to understand better the giant cicada imago ecology and to enhance the efficiency of $Q$. gigas control using a sound trap.

\section{Material and Methods}

\section{Cicadas Identification and Experiment Location}

Quesada gigas females were captured in 20 year coffee plantations - Coffea arabica L. var. Mundo Novo - located in São Sebastião do Paraíso municipality, Minas Gerais 
State, Brazil $\left(2013=20^{\circ} 57^{\prime} 54.32^{\prime \prime} \mathrm{S} ; 4^{\circ} 04^{\prime} 16.07^{\prime \prime} \mathrm{W} ; 2015=20^{\circ} 51^{\prime} 12.19^{\prime \prime} \mathrm{S} ; 4^{\circ} 04^{\prime}\right.$ $\left.29.15^{\prime \prime} \mathrm{W}\right)$. Cicada species identification was made using an identification key (Martinelli and Zucchi 1997).

\section{Sound Trap and Quesada gigas Capture}

A sound trap developed by Maccagnan (2008) was used for giant cicada capture. This acoustic device reproduces the sound emitted by $Q$. gigas males broadcasted by two drivers (Selenium, D250-X) attached to two horns (Selenium, HL14-25) coupled to a Sony CD player (CDX-S 2007 XG). This sound system has a frequency response between 400 and $9000 \mathrm{~Hz}$.

For cicada capture in 2013 , one sound trap was installed during $1 \mathrm{~h}$ in the morning period between two areas of one hectare each to attract $Q$. gigas females within a radius of $80 \mathrm{~m}$ (maximum estimated range of attraction of the trap - Maccagnan 2008). As attracted cicadas landed, they were trapped on raw cotton pieces placed around the trap and manually inserted into paper bags. The beginning of cicada emergence was determined when the male song started to be heard. In 2013, cicada emergence started on Sep. 30, 2013 and two captures were performed: the first capture was on Oct. 14, 2013 (15 days after the beginning of male emergence - DAME) and the second capture on Oct. 29, 2013 (30 DAME). Thirty cicada females per capture date were used for dissection.

In 2015, cicada emergence (determined when the male song started to be heard) started on Sep. 12, 2015 and the capture of cicadas was performed on 20 dates after the beginning of giant cicada male emergence (from Sep. 22, 2015 until Nov. 05, 2015) using an improved version of the sound trap (ECOSpray F-65; Idéia Máquinas Agrícolas; www.maquideia.com.br/ecospray) containing the same sound system described earlier attached to an insecticide applicator installed on a Fiat Strada pickup (Fig. 1a, b).

The capture of giant cicadas started in the morning period and the pickup was driven for $6 \mathrm{~h}$ over the entire 80 ha area. Captured cicadas were counted, separated into male or females and approximately 50 cicada females per capture date were inserted into paper bags and used for dissection.

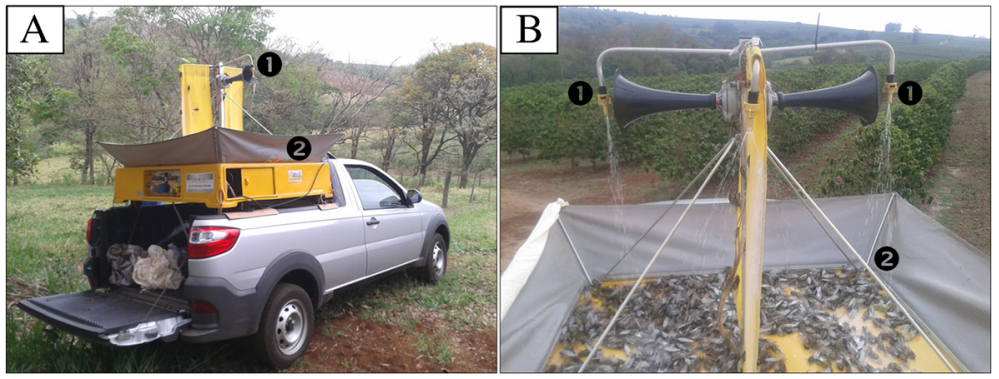

Fig. 1 Sound trap used for the capture of Quesada gigas in a coffee plantation. a General perspective of the sound trap attached to a pickup. b Details of the sound trap. IInsecticide sprayers in the front of the horn broadcasting $Q$. gigas males song; 2Recipticle for collection of dead cicadas and for insecticide recirculation 


\section{Cicada Dissection for Ovary Analysis}

Cicadas were anesthetized on ice and dissected on a Petri dish $(6 \mathrm{~cm}$ diameter; $1 \mathrm{~cm}$ height) filled with deionized water using scissors and tweezers. Wings, legs and the integument of the ventral abdomen were removed and the inner part of the exposed abdomen was washed with distilled water to separate the ovaries from other organs. After removed, ovaries were immediately photographed using a SC30 camera coupled to an Olympus SZ61 stereoscopic microscope. Ovarian maturation (color and presence of chorionated oocytes) and the number of chorionated oocytes in mature ovaries were observed.

\section{Results}

We observed that $100 \%$ of Q. gigas captured at 15 DAME had immature ovaries without chorionated oocytes in 2013. Immature ovaries were white in color (Fig. 2a), occupying a small volume of the abdominal cavity. At 30 DAME ovaries were mature, yellow in color and contained $428.2 \pm 45.7$ chorionated oocytes per mature female (Fig. 2b).

The width and height of mature and immature ovaries were similar, but the volume occupied by the mature ovaries full of chorionated oocytes in the abdominal cavity was greater than that volume occupied by immature ovaries. Similar to that observed in 2013, all females captured in 2015 had immature ovaries without chorionated oocytes until 14 DAME (Fig. 3).

In 2015, we detected the beginning of ovarian maturation at 17 DAME (only $20 \%$ of cicadas were mature). A transition phase from immature to mature females was at 17 and 19 DAME, as the proportion of mature females and the number of chorionated oocytes per female was not uniform in this period. These traits became uniform between 20 and 48 DAME, with the percentage of mature females above $80 \%$ and an approximate number of 600 to 1000 chorionated oocytes per female (Fig. 3).

The experiments conducted in 2013 indicated that Q. gigas both females and males are attracted to the sound trap but we did not quantified the number of males and females attracted to the sound trap in that year. In 2015, both males and females

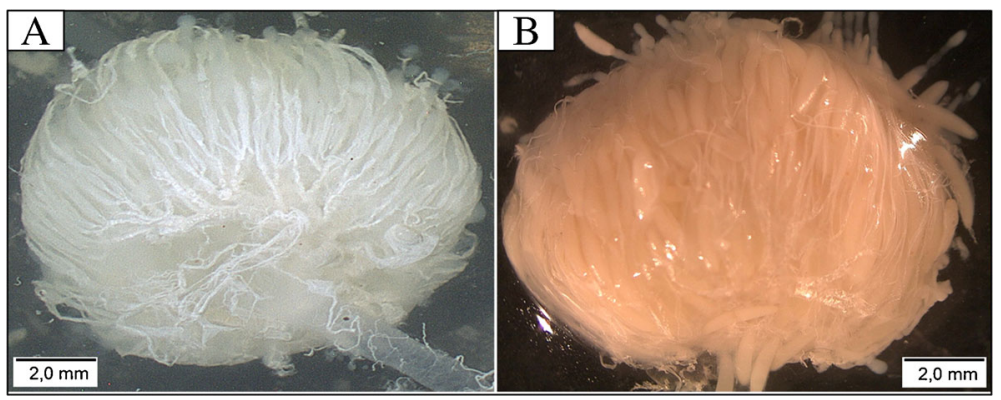

Fig. 2 Ovarian maturation status in Quesada gigas captured in 2013 at two dates after cicada emergence. a Immature ovary of Quesada gigas at 15 days after male emergence (DAME). b Mature ovary of Q. gigas with chorionated oocytes inside ovarioles at 30 DAME 


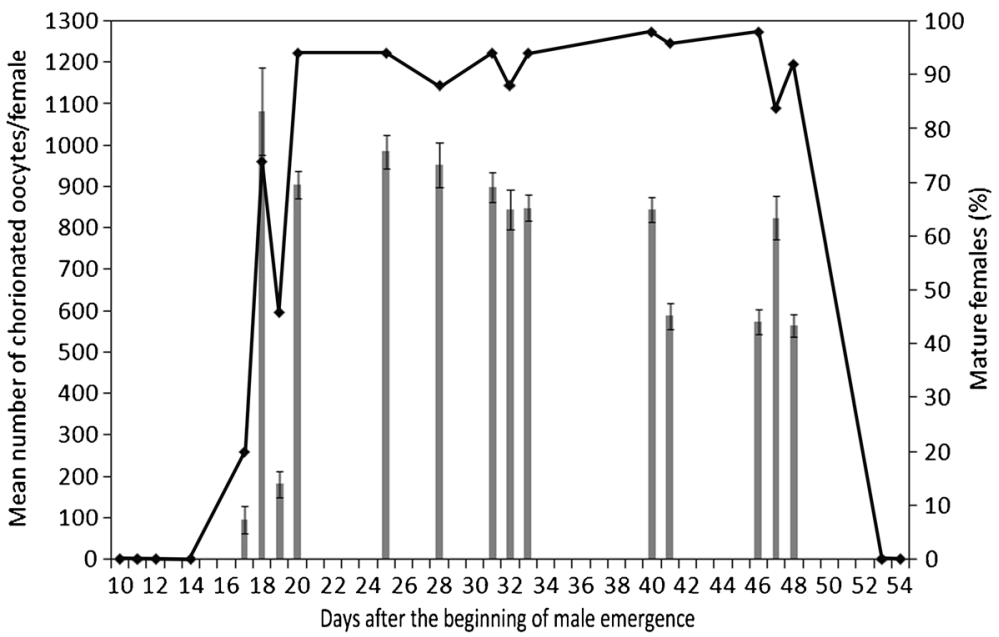

Fig. 3 Chorionated oocytes (mean number \pm SEM) per Quesada gigas female (columns) and percentage of mature females of $Q$. gigas (diamonds) captured at different days after the beginning of male emergence in 2015

attracted to the sound trap were counted and we observed that the attraction of males to the sound trap was superior to that observed for females at 10-12 DAME (Fig. 4).

\section{Discussion}

After becoming adults, insects (mainly anautogenous) may need a pre-oviposition period for ovary and oocytes maturation before they effectively oviposit (Swevers

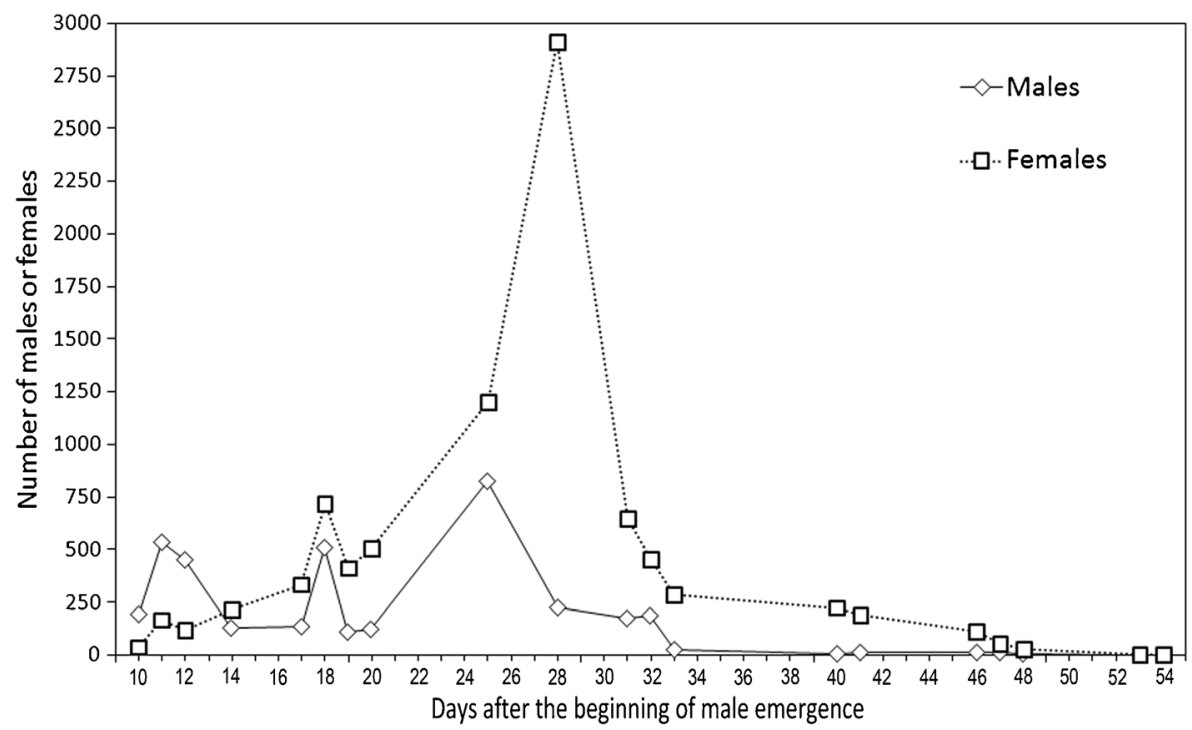

Fig. 4 Number of cicada males (diamonds) or females (squares) collected at different days after the beginning of male emergence using the sound trap in 2015 
et al. 2005). The observations made in two distinct years indicate that $Q$. gigas adult females start to become mature after approximately 14-15 DAME. As we could not control the age/date of emergence of females attracted to the sound trap, it was not possible to determine the exact pre-oviposition period (period between female emergence and beginning of oviposition) of Q. gigas. However, results suggest that $Q$. gigas females need a pre-oviposition period for ovary maturation because most females were not mature until 19 DAME. Moreover, results indicated that the emergence of $Q$. gigas females was apparently synchronized as most females (above $80 \%$ ) were mature from 20 until 48 DAME.

The attraction of males to sound traps that broadcast the male song to attract females was already reported (Alexander and Moore 1958; Ulagaraj and Walker 1973; Villet 1992). Male attraction to the sound trap can be associated to the sound emitted by females attracted to the sound trap to aid pair formation (Cooley 2001; Luo and Wei 2015), but this is probably not occurring in this case because more males were captured in the sound trap than females at 10-12 DAME (Fig. 4). The more suitable possibility is that males were attracted by the own male song as it is reported for periodical cicadas (Williams and Simon 1995). The crowding of Q. gigas males is probably done to create a chorus center, giving advantages for cicada mating or for predator satiation (Karban 1981; Williams et al. 1993). Moreover, the great number of males captured in the sound trap at 11 and 12 DAME in relation to females (Fig. 4) suggests an asynchronic emergence of males and females (protandrous emergence) of Q. gigas. Advantages conferred by protandry in periodical cicadas such as predator satiation are discussed by Williams and Simon (1995) and can also be associated with Q. gigas.

As observed for periodical cicadas (Williams and Smith 1991), we expect that Q. gigas females copulate just once. Despite the number of Q. gigas ovaries we dissected during the entire adult period in 2015, we could not distinguish if females attracted to the sound trap had previously copulated or not. The attraction of non copulated females to the sound trap can be clearly related to the first fertilization. In other insects, mating of previously copulated females can be related with multiple mating for sperm competition or the acquisition of extra nuptial gifts (Gwynne 1984) but the occurrence of multiple mating is not expected in cicadas (Williams and Smith 1991). If this is also true for giant cicada, we expect that only non fertilized cicadas were attracted to the sound trap, resulting in the killing of cicadas that have not copulated or oviposited.

Despite the use of the sound trap to understand better the post emergence ecology of $Q$. gigas, the attraction of a great number of cicada males and females to the sound trap during its reproductive period may result in the disruption of $Q$. gigas reproduction. The disruption of giant cicada reproduction can result in the reduction of eggs deposited in coffee fields reducing the infestation level of this pest below economic injury levels on its next generation. Similar to ours expectations, Mehdipour et al. (2016) observed the reduction of the number of eggs deposited by the grapevine cicada in infested branches of grapevine fields through the disruption of its reproductive behavior using an acoustic technology. The present work sheds light in part on the behavior and reproduction of $Q$. gigas and contributes in the development of a safe and rational control method based on a sound trap that may be incorporated in an integrated pest management (IPM) program. To contribute to the reduction of the population of Q. gigas in coffee fields, we can see the use of the sound trap from the beginning of 
Q. gigas male emergence until approximately 48-50 DAME. The use of the sound trap throughout this proposed period could disrupt chorus center formation, reduce the number of males available to copulate with females and capture the great number as possible of females.

Acknowledgements The authors thank Coordenação de Aperfeiçoamento de Pessoal de Nível Superior (CAPES) for the scholarship for SCA, Fundação de Amparo à Pesquisa do Estado de São Paulo (FAPESP) for research Grant (14/06137-0) and Empresa de Pesquisa Agropecuária de Minas Gerais (EPAMIG) for allowing the use of experimental areas. We also thank Professor Tomomassa Matuo for the donation of the improved version of the sound trap used in this study to the Departamento de Fitossanidade and two anonymous reviewers for their valuable contribution.

\section{Compliance with Ethical Standards}

Conflict of Interest The authors declare that they have no conflict of interest.

\section{References}

Alexander RD, Moore TE (1958) Studies on the acoustical behavior of seventeen-year cicadas (Homoptera: Cicadidae: Magicicada). Ohio J Sci 58:107-127

Cooley JR (2001) Long-range acoustical signals, phonotaxis, and risk in the sexual pair-forming behaviors of Okanagana canadensis and O. rimosa (Hemiptera: Cicadidae). Ann Entomol Soc Am 94:755-760

Decaro Junior ST, Martinelli NM, Maccagnan DHB, Ribeiro ESDBP (2012) Oviposition of Quesada gigas (Hemiptera: Cicadidae) in coffee plants. Rev Colomb Entomol 38:1-5

Foster SP, Harris MO (1997) Behavioral manipulation methods for insect pest management. Annu Rev Entomol 42:123-146

Gwynne DT (1984) Male mating effort, confidence of paternity, and insect sperm competition. In: Smith RL (ed) Sperm competition and the evolution of animal mating systems. Academic Press, Orlando, pp 117144

Ishaaya I, Horowitz AR (2009) Biorational control of arthropod pests: application and resistance management. Springer Netherlands, Dordrecht, p 404

Kahn MC, Offenhauser W (1949) The first field tests of recorded mosquito sounds used for mosquito destruction. AmJTrop Med Hyg 29:811-825

Karban R (1981) Flight and dispersal of periodical cicadas. Oecologia 49:385-390

Luo C, Wei C (2015) Intraspecific sexual mimicry for finding females in a cicada: males produce 'female sounds' to gain reproductive benefit. Anim Behav 102:69-76

Maccagnan DHB (2008) Cigarra (Hemiptera: Cicadidae): emergência, comportamento acústico e desenvolvimento de armadilha sonora. PhD Thesis, Faculdade de Filosofia, Ciências e Letras da Universidade de São Paulo

Maccagnan DHB, Martinelli NM (2004) Descrição das ninfas de Quesada gigas (Olivier) (Hemiptera: Cicadidae) associadas ao cafeeiro. Neotrop Entomol 33:439-446

Mankin RW (2012) Applications of acoustics in insect pest management. CAB Reviews 7:1-7

Martinelli NM (2004) Cigarras associadas ao cafeeiro. In: Salvadori JR, Ávila CJ, Silva MTB (eds) Pragas de solo no Brasil. Espiral Comércio de Livros, Passo Fundo, pp 517-541

Martinelli NM, Zucchi RA (1997) Cigarras (Hemiptera: Cicadidae: Tibicinidae). Distribuição, hospedeiros e chave para as espécies. An da Soc Entomol Brasil 26:133-144

Mehdipour M, Zamanian H, Farazmand H, Hosseini-Gharalari A (2016) Disruption of reproductive behavior of grapevine cicada, Cicadatra alhageos, by acoustic signals playback. Entomol Exp Appl 158:210-216

Metcalf ZP (1963) General catalogue of the Homoptera, fascicle VIII. Cicadoidea. Part 1. Cicadidae. Section 1. Tibiceninae. North Caroline State College Contribution 1502:1-585

Offenhauser WH, Kahn MC (1949) The sounds of disease-carrying mosquitoes. J Acoust Soc Am 21:259263 
Reis PR, Souza JC, Venzon M (2002) Manejo ecológico das principais pragas do cafeeiro. Informe Agropecuário 23:83-99

Souza JC, Reis PR, Silva RA (2007) Cigarras-do-cafeeiro em Minas Gerais: histórico, reconhecimento, biologia, prejuízos e controle. Boletim técnico 80, 2nd ed. EPAMIG, Belo Horizonte, p 48

Swevers L, Raikhel AS, Sappington TW, Shirk P, Iatrou K (2005) Vitellogenesis and post-vitellogenic maturation of the insect ovarian follicle. In: Gilbert LI, Iatrou K, Gill SS (eds) Comprehensive molecular insect science, vol 1. Elsevier Pergamon, Oxford, pp 87-155

Ulagaraj SM, Walker TJ (1973) Phonotaxis of crickets in flight: attraction of male and female crickets to male calling songs. Science 182:1278-1279

Villet MH (1992) Responses of free-living cicadas (Homoptera: Cicadidae) to broadcasts of cicada songs. J Entomol Soc South Afr 55:93-97

Walker TJ (1988) Acoustic traps for agriculturally important insects. Fla Entomol 71:484-492

Williams KS, Simon C (1995) The ecology, behavior and evolution of periodical cicadas. Annu Rev Entomol 40:269-295

Williams KS, Smith KG (1991) Dynamics of periodical cicada chorus centers (Homoptera: Cicadidae: Magicicada). J lnsect Behav 4:275-291

Williams KS, Smith KG, Stephen FM (1993) Emergence of 13-yr periodical cicadas (Cicadidae: Magicicada): phenology, mortality, and predator satiation. Ecology 74:1143-1152 